\title{
On the Market for Principles of Economics Textbooks: Innovation and Product Differentiation
}

\section{Joseph E. Stiglitz}

I have been asked to prepare a few remarks reflecting my views on the current state of principles of economics textbooks. It goes without saying that, given the plethora of textbooks available on the market, I have not read in detail all of them, and this is not the occasion to provide a detailed criticism of any single textbook. My remarks will, of necessity, be somewhat impressionistic, but they reflect impressions developed over years of discussing with colleagues at a large number of colleges and universities the problems presented by the modern American principles of economics textbook.

I want to put forward two theses, as well as raise several unresolved questions and issues. The first thesis is that the market for principles textbooks provides a good example of one of the central paradigms of modern economics, that of monopolistic competition, and it reflects both the strengths and weaknesses that economic theory would have led us to expect to arise in such a market.

The market is characterized by a high degree of product differentiation: textbooks differ in size, level, and organization. Although the majority of books present macroeconomics before microeconomics, the instructor who prefers the reverse order can find a variety of books that present microeconomics before macroeconomics. And, although the majority of books are written on the presumption that there will be a full-year course in economics, there are a number of books written for the one-semester market. There are books aimed at the junior college market, and books aimed at students who enter with a background in calculus. Indeed, not surprisingly, publishers focus more of their attention on this product competition than they do on conventional price competition (which remains at the center of the discussion of the books.)

This product competition has served, moreover, to stimulate innovations in a number of important dimensions. A variety of pedagogic aids have been introduced that facilitate the student's ability to learn the material and that, at their best, stimulate student interest in the subject. Not that all such innovations are successful. Properly done, four-color printing might

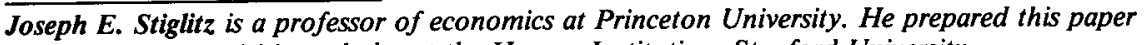
while serving as a visiting scholar at the Hoover Institution, Stanford University. 
enhance learning. When it is not done well, such printing appears bizarre and distracting. Well-selected cartoons may make a point in an effective way, which students will remember; cartoons that are not well selected, however, detract from the seriousness of the subject and, if not an impediment to learning, at least waste valuable space that could be better used. Boxes may serve as a useful break from the main flow of the argument of the chapter, but when more than a third of the textbook is devoted to boxes, the student may have a hard time finding the main flow.

More generally, market forces have stimulated some very good economists and publishers to think hard about what kinds of books will sell well, that is, will do well relative to existing books. This has resulted in books that, for the most part, are of a high publishing standard, with layouts and printing styles that are truly attractive. Anyone who doubts this need only contrast the textbooks of the current generation with those of seventy-five, or even fifty, years ago.

The books, if not well written, are at least clearly written, with the level of writing undoubtedly declining over the years to reflect the corresponding decline in reading levels. This raises the question of whether we academics should have acquiesced as quickly as we have to those lowered standards. Have we, by our acquiesence, contributed to the lowering of these reading levels? The typical economics professor claims that his job is to teach economics, taking as given the reading and mathematical backgrounds of his students. And the publishers, with perhaps even more justification, claim that they reflect the revealed preferences of their consumers.

A central result of the theory of monopolistic competition, however, is that although product competition may well result in product diversity, the range of product offered may not exhibit any optimality properties. ${ }^{1}$ The early literature on monopolistic competition (Hotelling) identified one important problem: there may exist a "centripetal" force, with too many similar products at the center of the market, two few products at the fringes.

I raised earlier the issue of innovation, suggesting that market forces provided a strong stimulus for new ideas. Again, the literature on market innovation has shown that its market equilibrium also may lack certain optimality properties. Resources get allocated to some socially desirable innovations, but there are other, even more socially valuable, innovations that receive inadequate resources. Two central concerns in this literature are risk and the appropriability of returns. An innovator, someone, like Samuelson, who departs significantly from the pre-established norm, undertakes a risk. If the market fails to find his approach attractive, the huge investment in time (and the huge investment of resources of his publisher) is lost. Indeed, one might argue that the increasingly high quality of the standard book (with all the paraphernalia that accompany it) has served as an effective entry barrier to approaches that represent significant departures from prevailing textbooks. On the other hand, if the book is successful, it will quickly be imitated. Clones, catering to a variety of special needs, will be developed. 
Books simplifying (perhaps oversimplifying) the basic ideas will be marketed, as will books adorning the basic ideas with more mathematics and graphs. One-semester versions will appear, as will versions aimed at the junior college market. The historical experience-including the cloning of Samuelson-suggests that textbook innovators (and other publishers) do reap some returns, but the returns they reap may be only a fraction of the total returns.

This brings me to my second, and I am sure, far more controversial thesis: that, at least at the present time, the market for principles of economics textbooks reflects these market failures. In order to stimulate discussion, I will state the argument somewhat starkly and contentiously, but there is, I think, more than a grain of truth in what I am about to say.

The current set of textbooks, by and large, are clones of the one great textbook written in this century, Samuelson's, written almost forty years ago. There are, to be sure, adaptations, important adaptations, on his basic format. ${ }^{2}$ I have already stressed several of these, the adaptations to different levels (usually downward) and the introduction of pedagogic aids. There are others: principles textbooks have incorporated the passing fads and fashions of the profession. When poverty was in, in went a chapter on poverty. When radical economics was in, in went a chapter on Marxian economics. When monetarism was in, in went a discussion of monetarism. When rational expectations was in, in went discussions of rational expectations, scattered at appropriate places throughout the textbook. Although supply-side economics may not have ever been in vogue among the economics profession, in the period in which it was in vogue in the political arena, appropriate attention (if only to debunk it) was paid.

Do not misunderstand me: it is important that textbooks speak to the current concerns of the students, and the fact that our textbooks so quickly reflect these concerns is to be commended. But this kind of adaptation should not be confused with a fundamental change in the contents of the principles textbook.

Indeed, the growth of the principles textbook, to incorporate this growing list of changing concerns, has not been without its costs: the size of the textbooks has grown, often to the point where the books are unwieldy and where the central messages of economics are, if not lost, at least obscured. The encyclopedic nature of modern textbooks has been a recurring theme in this conference.

The market forces for imitation, which Hotelling identified so forcefully a half century ago, seem compelling in this market. If textbook $A$ has a chapter on poverty, why should not textbook B? Those who do not want to use the chapter are not compelled to do so. But there will be some professors who want to have a unit on poverty, and textbook authors and publishers want to be sure that the absence of the chapter on poverty does not provide the basis for discriminating in favor of textbook $\mathrm{A}$ over textbook $B$.

Indeed, market forces may actually serve to inhibit important innova- 
tions and to promote a high degree of standardization of the curriculum: ${ }^{3}$ courses have been designed around the current set of textbooks. Any fundamental innovation would require a fundamental alteration in the courses. Given the costs of such alteration, which would have to be borne by the professor, and the uncertain benefits, professors may be reluctant to do so. Publishers (and textbook writers) anticipating that, know that only a limited degree of innovation is acceptable in the textbook, if it is to be widely adopted. So long as the book remains basically a clone of Samuelson's (or a clone of a clone of Samuelson's), it at least has a chance of success. In more technical jargon, we may be in an inefficient Nash equilibrium.

In fact, the process of textbook writing (and marketing) has become routinized to the point that, in the preparation of a new textbook, detailed comparisons with perceived major rivals are often made of the amount of space devoted to each topic. Major deviations need to be justified.

This process of cloning Samuelson may, at one time at least, not have been altogether bad. Some of the clones enabled a version of these ideas to reach out to schools and students that Samuelson probably would not have reached, or not reached as effectively.

But forty years have passed since Samuelson wrote his great textbook, and economics has changed, and the economy has changed, and the textbooks have, at best, attempted to graft some of these changes onto the existing format. The result is the kind of dissatisfaction that, I think, underlies the call for the conference in which we are participating today.

In the remaining time, I want to list several of these changes. There are so many that I can touch only on the more important-and more obviousones. And because they are the more obvious ones, I want to emphasize that they have not gone unnoticed in principles textbooks. The question is, how have they been incorporated? As appendages, treated in separate chapters, which almost inevitably get squeezed out as the semester rushes to a close? Or as central aspects of modern economics?

Let me begin with the first set of changes, those to our economy. The outstanding event has been the internationalization of our economy. Can a closed-economy model provide the students an adequate basis for understanding the macroeconomic problems facing the United States today? Should not our minimal goal in teaching a principles course be that the students possess enough economic understanding to make some sense of the major economic events reported in the newspaper? Can they do that today without a minimal understanding of exchange rates, international capital markets, the relationships between deficits and exchange rates, and so forth? Professor Bell has emphasized this in her paper, and Professor Boskin has drawn attention to it, so I will say no more about it here.

The second change has to do with the importance of technical change in our modern economy. More than fifty years ago, Schumpeter complained loudly and clearly about the textbooks of his day, saying that they were based on a competitive paradigm in which there was no technological change. Technical change, as he argued, is inevitably associated with imperfect com- 
petition. It was not only that technical change was ignored but that the economic theory that was presented in the textbooks was not "consistent" with the kinds of market structures that were inevitably associated with technical change.

But if these complaints had some validity in Schumpeter's day, how much more do they seem apropos today! The one major sector of the economy in which the competitive price-taking hypothesis might have had general acceptance in his day, agriculture, has shrunk in importance, to the point where it accounts for but a few percentage points of the gross national product; and government intervention has grown to the point where that sector can hardly be considered today as an example of the competitive paradigm.

The past forty years have seen not only important changes in our economy but equally important changes in economics (some of them reflecting these changes in the economy.) A central problem is to distinguish the fads and fashions-which, as I have commented, do regularly get reflected in the textbooks-from the major "permanent" lessons to be drawn. The question of what are the central messages that we wish to convey to our students in the principles course needs to be asked, over and over again, and the central structure of the principles textbook needs to reflect these central messages. I would argue that among the central messages that we would wish to convey today are many that were present in Samuelson's original textbook, but there are several new ones; also, the overall perspective within which these ideas are to be cast differs today, in some important respects, from that of forty years ago. I cannot describe completely to you what $I$ have in mind in the limited amount of time I have available-that itself would be a prospectus for a textbook, a prospectus that I suspect might have market value. Given our current laws on intellectual property rights, I also suspect my disclosure might inhibit my ability to appropriate the full rents.

Accordingly, the themes, issues, and perspectives that I will stress are among those that the profession widely agrees should be better reflected within principles textbooks. The difficulty lies not so much in the recognition of the inadequacy of the current textbooks, but in incorporating these perspectives in a coherent and understandable fashion, in integrating them into the core of the subject, not as appendages, separate chapters to be discussed, if time allows-which it almost never does.

The first of these is the basic dichotomy between macroeconomics and microeconomics. This is a topic on which $I$ and others have written extensively. There appears to be a consensus that the split between the two, the differences in assumptions and conclusions, is unsatisfactory, from both an intellectual and a pedagogic point of view. The problem arises in developing a way of reconciling the two, and in developing a method of presenting that reconciliation at a level that is appropriate to a principles textbook.

In surveys of reactions to any textbook in any field, one standard response is that the textbook devotes too little attention to the particular field of interest of the individual being surveyed. The economists surveyed 
often seem to be unaware of the resource allocation problem that faces any textbook writer: how to allocate the relatively scarce space available in the textbook of reasonable size-and the relatively scarce time of the students. It is therefore with some trepidation that I raise the next set of issues, what I see as the lack of appropriate attention to the problems of information and uncertainty in the currently popular principles textbooks. But I would argue that there is a difference: these issues of information and uncertainty have been at the center of theoretical, and indeed even of much applied, research in economics over the past two decades. They have reshaped the way that we think about many of the central issues. They are not properly treated-as some of the better textbooks have tried to do-as "additional topics" covered in separate sections or separate chapters. They are, I would argue, at the core of the central problem of economics. We cannot understand how financial markets or labor markets function without paying due respect to these considerations.

Indeed, two of the topics that should be central in any textbook in economics make little sense in a world in which there is perfect information and no uncertainty: issues of economic incentives and of the processes by which decisions get made. (Though these are topics on which I have written extensively, I hope that this argument will not be seen as self-serving.)

My impression is that there is indeed a growing consensus that the view of economics encapsulated in Samuelson's book and its clones and descendants differs in significant ways from the view that has emerged within the profession during the past one or two decades. (Of course, the theory of product differentiation would predict that $I$ would try to claim as much. The theory is indeed a powerful one: it provides not only an interpretation of what we observe in the market for principles textbooks, but also an interpretation of this paper about what we observe in the market for principles textbooks.) As I said, the problem is not so much articulating the deficiencies of the current set of textbooks, but remedying them: Much of the literature of the past two decades has been highly technical. And often it seems not even the authors of the paper are clear about what insights should be gleaned from their paper. The problem is not only to extract the central insights and present them in a way that is accessible to the beginning student. This much could be done in the kinds of additional chapters and sections that, as I said before, have become so fashionable and that often seem to clutter up even the better textbooks. The challenge is to incorporate these considerations into the principles that should be the core of the principles
textbook.

In the preceding remarks, I have tried to focus my attention on what I see as some of the central changes that are needed, to reflect more adequately important changes that have occurred during the past forty years in the economy and in the economics profession. (It should be clear that the changes in the economy I discussed earlier, the increasing importance of international trade and capital movements and of technical change, have to some extent been reflected in changes within the profession. These deficien- 
cies in the principles textbooks would thus appear to be doubly important.)

There are other changes in emphasis and balance where I see many, if not most, of the current textbooks differing from my ideal, but once the more fundamental changes I have suggested are accomplished, I am more sanguine about the market's ability to reflect these other changes. I do not expect that all the textbooks would do so, nor do I see any reason why they should. For instance, I think a persuasive case can be made that important insights into the nature of the resource allocation process can be gleaned by understanding how different economies differ; there are a few textbooks that presently emphasize, or at least deal quite adequately, with this kind of comparative approach. It is important that this option be available, but I think it unreasonable to expect most textbooks to be so oriented.

I also think it is important for students to understand more clearly how it is that we know what we know, and why it is that economists differ among themselves: why it is, in other words, that there are some important questions to which we do not know the answers. To grasp this, students do not need to be taught statistics, but they need to be taught some of the underlying statistical ideas. They have to understand how the data that economists use are generated. I suspect that the better textbooks of the future will do a good job in conveying these ideas, as some of the better textbooks now do, but given the nature of the market, it would be unrealistic to suppose that all, or even most, textbooks will succeed in doing so.

Let me conclude by expanding upon an issue I raised earlier: There are important simultaneity problems. The textbooks that are available affect the nature of the principles course. But the textbooks that are available are also a reflection of the nature of the principles course and of how decisions about principles textbooks are made. And these courses are, to a large extent, a reflection of the nature of the academic economics profession in the United States today. To what extent, then, are the deficiencies that some see in the textbooks really deficiencies that we see in ourselves? Are the ways in which our textbooks have grown, adding a chapter here on one topic, a section there on another, merely a reflection of how we chase some fads and fashions, pursuing this one for a few years, and that one for a while? Are they, too, a reflection of how textbook adoptions get made in so many colleges and universities by the vote of a committee?

Too much introspection always makes us uneasy. All of this having been said, the hard task lies ahead: It is easy to criticize; the difficulty is to do a better job, to write the better textbook that we all (at least, those of us who have not already written a textbook) agree should be written.

\section{NOTES}

1. Under certain restricted conditions, Dixit and Stiglitz (1977) have shown that monopolistic competition yields a constrained Pareto optimum. It should be emphasized, however, that the main thrust of their paper was to show that more generally it does not yield a constrained Pareto optimum.

2. I would also be remiss not to note that there are some important exceptions.

3. The recent work of Shapiro and Katz has provided an excellent discussion of the economic issues entailed in standardization. 
Copyright of Journal of Economic Education is the property of Heldref Publications. The copyright in an individual article may be maintained by the author in certain cases. Content may not be copied or emailed to multiple sites or posted to a listserv without the copyright holder's express written permission. However, users may print, download, or email articles for individual use. 